\title{
To Jeremy: In Your Honor
}

\author{
Mary Ellen O'Toole, $\mathrm{PhD}^{1,2}$
}

$\mathbf{T}$ HE RECENT LOSS of our Associate Editor, Dr. Jeremy Richman, to suicide has been devastatingly painful for so many of us. We loved Jeremy. Everything about him was special and inspirational.

As many of you know Jeremy lost his beautiful 6-year-old daughter, Avielle, in the 2012 Sandy Hook School shooting. After losing Avielle, Jeremy became an advocate for brain health and finding out the "whys." He was passionate and laser focused on this path toward understanding, treatment, and prevention of violence. He was truly a man on a mission. Jeremy's work was so critical because he really got it. He understood the long-term effects of horrible violence, and he knew the study of the brain held so many answers.

We were so proud at Violence and Gender to partner with Jeremy and The Avielle Foundation. We shared similar goals and objectives, and a passion for getting the answers using a multidisciplinary platform to bring experts together to understand mass shooters from a $360^{\circ}$ perspective.

The loss of Avielle, and now Jeremy, is immeasurable, profound, and generational. There is no telling what these two human beings could have accomplished in their life times and how much they would have contributed to humanity.

I believe this type of violence is a public health crisis and should be treated as such. I could stop right here and just say that the pain, agony, and forever loss to the victims and their families cry out to make these public health crises, and that should be enough justification. But there is more reason for this. The damage inflicted on all of us by this type of violence is corrosive to our own spirits. We see humanity fade a little bit more each time one occurs. I know my own sense of sadness and yes, even hopelessness, after each new mass shooting occurs. I have been studying these cases for nearly 25 years, and sometimes I feel, to what end? They are not going away, and the quality and callousness of these events are getting worse and worse. It is daunting to see the hatred that accompanies these events, their cold-blooded nature, the manifestos in which these shooters spew out their hateful injustice collecting, and the swaggering red flags we see so often on their social media platforms created days or even hours before the event. You see, we are all victims to this horrible violence.

I know Jeremy Richman's work was good and selfless, and motivated for all the right reasons. I wonder whether he too felt the same sense of loss and sadness as many of us do watching these shootings go on and on. The hatred continues, lives are lost, and one more gun is purchased by the next shooter.

When we talk about mass shootings, I do not think we consider the residual impact these cases have on us, and particularly the people closest to those who lost a loved one. The loss of a loved one through such coldblooded and avoidable violence must be a pain for which Webster has no definition, and that was Jeremy's loss.

These crimes eventually fade from the headlines, but their impact does not. Affected families must live with the loss of their loved ones forever-generations into the future. Their emotions of grief, sadness, shock, depression, and surrender might seem faded to those around them. But they are not. Their pain is baked into their family's genealogy. The painful longevity of the impact on people cannot be overemphasized. I believe we are underestimating the destructive implications and long-term impact of these crimes on us as individuals, and as a society. Our injuries might be invisible as most emotional scars are, but their pain and damage to us are as real as any physical wound, and they are cumulative after each incident. They are creating generational damage, and we are all affected.

We cannot count the casualties by counting only those who died during a mass shooting. To ignore the generational impact of these cases would be unconscionable. These cases have a cumulative effect on all of us and even on future shooters. There is a contagion effect for these crimes. They are aspirational for future shooters but increasingly debilitating for those of us who are forced to stand by and watch. For those of us like Jeremy, whose life work was to study the brain and figure out the "whys," each successive case after Sandy Hook must have been another break to his heart.

Crimes that create such societal damage must be considered a public health concern and, therefore, should be treated, funded, and researched as a crisis. These are not just National Rifle Association (NRA) issues, mental health issues, or law enforcement issues. These cases, their motivations, their causation, and their impacts are like a cancer that can morph and evolve with each new treatment methodology, and their impacts to us can become increasingly more deadly to our emotional wellbeing and to our society. We cannot be OK with that.

Jeremy Richman dedicated his life to brain health and finding the answers to stop these crimes. In honor of Jeremy Richman, can we not all commit to preserving his legacy by

\footnotetext{
${ }^{1}$ Director of Forensic Science Program, George Mason University, Fairfax, Virginia.

${ }^{2}$ Retired FBI Special Agent/FBI Profiler, Behavioral Analysis Unit.
} 
continuing his efforts the way he would want them to be continued?

Thank you, Jeremy, for all of your work. We love you and Avielle. We will do our very best to continue your work, with the same enthusiasm and passion you had. We know how important it was to you, your family, and The Avielle Foundation. In our hearts and souls, you and Avielle will never be forgotten or lost to time. You showed us the way - and now, sadly, we take the baton from you, and with all of our strength and heaviness of heart, through eyes filled with tears, we will push forward in your honor and memory.

\section{Disclaimer}

The views expressed in this piece do not represent the views of the Federal Bureau of Investigation. They are solely the views of Dr. O'Toole.

Address correspondence to: Mary Ellen O'Toole, PhD Editor-in-Chief Violence and Gender

E-mail: violenceandgender@liebertpub.com 